\title{
Experimental investigation of unsteady flow phenomena in a three-stage axial compressor
}

\author{
R Niehuis ${ }^{1}$, A Bohne ${ }^{1}$ and A Hoynacki ${ }^{2}$ \\ ${ }^{1}$ Institute of Jet Propulsion and Turbomachinery, RWTH Aachen University, Aachen, Germany \\ ${ }^{2}$ Siemens AG, Power Generation G51, Muelheim a. d. Ruhr, Germany
}

\begin{abstract}
In the past years, a three-stage axial compressor equipped with a modern controlled diffusion airfoil (CDA) blading has been investigated in much detail, applying state-of-the-art steady and unsteady measurement techniques, at RWTH Aachen University. The compressor under investigation exhibits design features of real industrial compressors. By performing high-resolution measurements both in space and time, a thorough insight into various flow phenomena in the compressor has been achieved, leading to a better understanding of various flow phenomena such as rotor-stator interaction, tip clearance flow and viscous flow effects in a multistage compressor environment. After a short summary of some performance characteristics at design and off-design, this paper focuses on the analysis of interaction phenomena present in the threestage axial compressor. The interaction phenomena are described on a more global scale. In order to quantify the upstream and downstream influence of the three rotor blades, a suitable parameter is presented.
\end{abstract}

Keywords: high speed axial compressor, unsteady flow, rotor-stator interaction, wake stability

\section{NOTATION}

\begin{tabular}{|c|c|}
\hline B1, B2, B3 & blade $1,2,3$ \\
\hline$f$ & frequency $(\mathrm{Hz})$ \\
\hline IGV & inlet guide vane \\
\hline$K_{\mathrm{p}}$ & $\begin{array}{l}\text { characteristic parameter defined in } \\
\text { equation (1) }\end{array}$ \\
\hline$\dot{m}$ & mass flow $(\mathrm{kg} / \mathrm{s})$ \\
\hline $\mathrm{OP}$ & operating point \\
\hline$p$ & pressure \\
\hline$\tilde{p}$ & amplitude of pressure fluctuations \\
\hline & fluctuations of quasi wall shear stress \\
\hline V1, V2, V3 & vane $1,2,3$ \\
\hline
\end{tabular}

\section{Subscripts}

EA

INA

$\mathrm{m}$

r.m.s.

$\mathrm{S}$

$\mathrm{t}$ ensemble-averaged value

international norm atmosphere

spatially and temporally averaged value

root mean square value

static condition

stagnation condition

The MS was received on 31 March 2003 and was accepted after revision for publication on 7 April 2003.

*Corresponding author: Institute of Jet Propulsion and Turbomachinery, RWTH Aachen University, Templergraben 55, D-52062 Aachen, Germany.

\section{INTRODUCTION}

In the field of multistage compressor development, remarkable effort is spent on achieving higher efficiencies and wider operating ranges. In order to consider all relevant aspects of the highly complex three-dimensional flow within the design process, especially viscous and unsteady flow phenomena, a good understanding of the flow physics as well as the availability of highly sophisticated and well-calibrated design tools is essential. The development of reliable design tools, however, requires detailed experimental data of all relevant flow phenomena in adequate multistage components.

The flow in turbomachines is not only highly threedimensional but also features complex unsteady phenomena due to the existence of stationary and rotating bladerows. In a multistage environment, strong interactions exist between the different bladerows, which are superimposed on other three-dimensional effects and strongly influence the whole flowfield. One aspect of rotor-stator interaction is caused by the wakes generated by the airfoils upstream of a bladerow. The wakes strongly influence the inlet flow at the next bladerow, resulting in periodic total pressure fluctuations and periodic variations in incidence angle. Additionally, the turbulence level continuously increases along the flow path on account of the wakes (see, for example, reference [1]). Altogether, this alters the flow through the blade passages and leads to temporal changes in the airfoil pressure distribution. The wakes are stable flow phenomena and are 
convected through the downstream bladerows. They usually still exist in the exit plane of the next bladerow downstream, and thus may also influence the flow of the second bladerow (or even further bladerows) downstream. Depending on the indexing of this bladerow relative to the bladerow where the wakes are generated, this may lead to flow situations known as 'clocking phenomena'. Although all aspects of this interaction are not fully understood, nowadays it is well known that, by indexing stator vanes and/or rotor blades respectively the efficiency of a multistage turbomachinery component can be altered and improved if indexed in the right way (see, for example, references [2-5]).

In the sidewall regions both at hub and tip of a turbomachine, secondary flows are generated on account of the boundary layers on the sidewalls and the blades. Secondary flows usually exhibit discrete vortices known as horseshoe vortices, passage vortices and trailing edge vortices. In the case of radial clearances, additionally tip clearance vortices may arise. In the exit plane of a bladerow, typically numerous discrete vortices exist which interact with each other and influence the flow through a bladerow placed downstream. Owing to the different frames of reference of adjacent bladerows, this also results in a complex time periodic interaction.

The interaction phenomena discussed so far influence the flow in bladerows located downstream. Another form of interaction between adjacent bladerows is related to the potential upstream influence of blades. Hoynacki et al. [6] have shown that this may lead to a significant upstream interaction, influencing the pressure field and boundary layer development of an upstream bladerow in such a way that the transition process of the boundary layers on the blade surface is modulated in a time periodic way.

On account of the fact that the transition process in the boundary layers of modern axial compressor blades fundamentally influences the range of operation as well as the achievable efficiency and pressure rise, this kind of interaction needs to be carefully taken into consideration in the design of airfoils. If blade loading is too high, the adverse pressure gradients can cause severe boundary layer separation on the airfoils. In this respect, a correct prediction of the boundary layer behaviour is mature. Highly sophisticated computational fluid dynamics (CFD) methods for the simulation of viscous flow are commonly used as design tools. However, the prediction of position and length of transition as well as unsteady flow phenomena is currently not adequately considered.

Detailed investigations in industry-like compressors are difficult owing to small blade heights and axial gaps, short time-scales and high costs of operation. The complexity of the phenomena described above led to the study of individual aspects in simplified experimental environments, such as cascades and large-scale, low-speed compressors. The transferability of the achieved results to real machines, however, is confined, since interaction phenomena are simultaneously influenced by different factors such as Reynolds number, blade loading, freestream turbulence, pressure gradient and unsteadiness.

\section{DESCRIPTION OF THE TEST FACILITY}

At the Institute of Jet Propulsion and Turbomachinery at RWTH Aachen University, a high-speed, three-stage axial compressor with inlet guide vanes (IGVs) and controlled diffusion airfoils (CDAs) was built with the objective of improving the understanding of the complex three-dimensional and unsteady flow phenomena in an industry-like multistage compressor by using detailed and highly sophisticated measurements [1]. All bladerows were designed by an inverse design method. In Fig. 1 the cross-sectional view of the three-stage axial compressor is shown. Because of the limited axial space (owing to the limited axial space in the laboratory), the flow is guided from a perpendicular to an

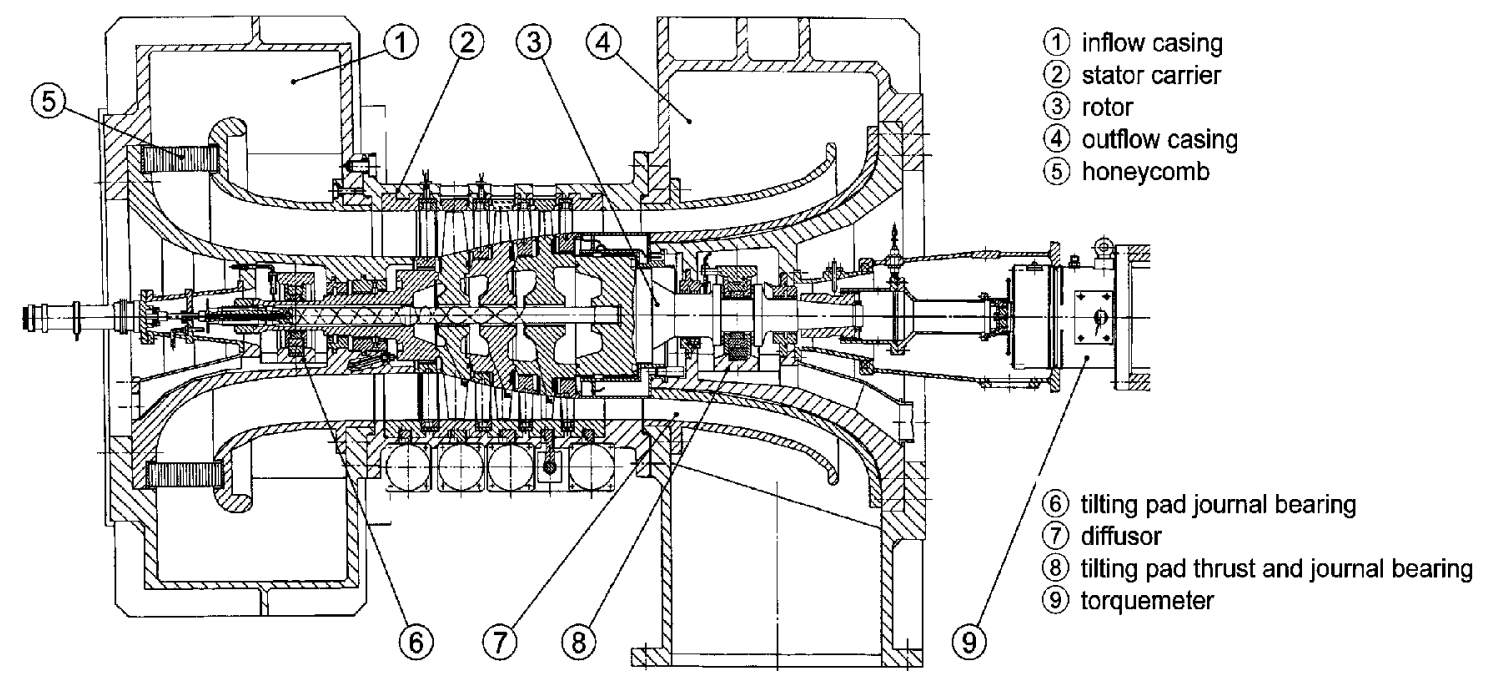

Fig. 1 Three-stage axial compressor at RWTH Aachen University 
Table 1 Characteristic design parameters

\begin{tabular}{llll}
\hline Corrected rotor speed & $17000 \mathrm{~min}^{-1}$ & Corrected mass flow & $13.4 \mathrm{~kg} / \mathrm{s}$ \\
Overall total pressure ratio & 2.03 & Power input & $920 \mathrm{~kW}$ \\
Total pressure ratio 1st stage & 1.30 & Maximum inlet Mach number (R1, tip) & 0.89 \\
Total pressure ratio 2nd stage & 1.28 & Tip diameter & $387 \mathrm{~mm}$ \\
Total pressure ratio 3rd stage & 1.22 & Circumferential tip speed & $345 \mathrm{~m} / \mathrm{s}$ \\
Height of first blade & $86.0 \mathrm{~mm}$ & Height of last vane & $43.7 \mathrm{~mm}$ \\
Chord length of first blade & $50.0 \mathrm{~mm}$ & Chord length of last vane & $26.0 \mathrm{~mm}$ \\
Reynolds number first blade & $9.6 \times 10^{5}$ & Reynolds number last vane & $3.8 \times 10^{5}$ \\
\hline
\end{tabular}

axial direction by an inlet duct. The inlet duct configuration is equipped with a honeycomb flow straightener and an axial duct as long as possible in order to compensate for distortions caused by the two-sided radial inflow. This arrangement without any struts provides a homogeneous flow distribution at the IGV inlet. The IGVs and the stator blades are mounted in inner shroud rings with no radial clearances both at hub and casing. The rotor radial tip clearances are less than $0.3 \mathrm{~mm}$ during operation, yielding a relative clearance of 0.35 per cent for the first rotor row and 0.49 and 0.64 per cent for the subsequent rotor rows.

The compressor runs in a closed loop. The mass flow is adjusted by a throttle. In order to control the total inlet conditions during the measurements, an automatic control system for temperature and pressure is used. A torquemeter is used in order to determine the input power of the threestage axial compressor.

Some characteristic design parameters of the compressor are summarized in Table 1, and more details are provided by Hoynacki et al. [1].

The measured performance map of the compressor is shown in Fig. 2. Operating point OP1 is very close to the design point on the 100 per cent speed line. The small difference in mass flow at identical pressure ratio is due to the fact that the effect of sidewall blockage was not considered during the design of the compressor. The compressor was higherto investigated in great detail by steady and unsteady measurement equipment at five different operating

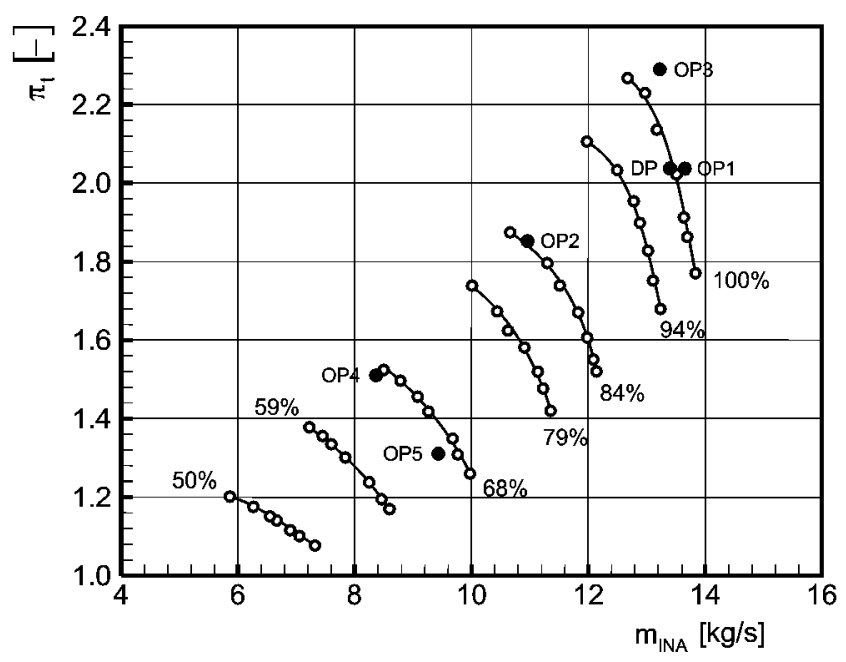

Fig. 2 Performance map of the three-stage axial compressor points (OP1 to OP5), as indicated in Fig. 2. Hoynacki et al. [1] presented some experimental results for OP1 and OP2. Since then, three additional operating points have been investigated in the same detail, such that detailed measurement results are now available for two operating points at 100 per cent speed, close to design (OP1) and close to surge (OP3). In order to provide detailed measurement results at low off-design speed, two operating points at 68 per cent speed were chosen, i.e. one operating point close to surge (OP4) and another one close to choke (OP5). OP2 represents an operating point close to surge at 84 per cent speed, but this will not be discussed in this paper. Operating points OP2 to OP5 indicate extreme points in the performance map where stable operation of the compressor could still be obtained. This paper will focus on the interpretation and analysis of the operating points on the 100 and 68 per cent speed line.

\section{INSTRUMENTATION}

For detailed experimental investigation of the flowfield, with emphasis on three-dimensional viscous and unsteady flow phenomena in the multistage compressor, the flowfield upstream and downstream of each bladerow was traversed with pneumatic probes with high resolution in space. Miniaturized Pitot and three-hole pressure probes were used in order to resolve the boundary layer at hub and casing, whereas five-hole pressure probes were applied to measure the three-dimensional flowfield over approximately 85 per cent of blade height (see Fig. 3). Additionally, triple

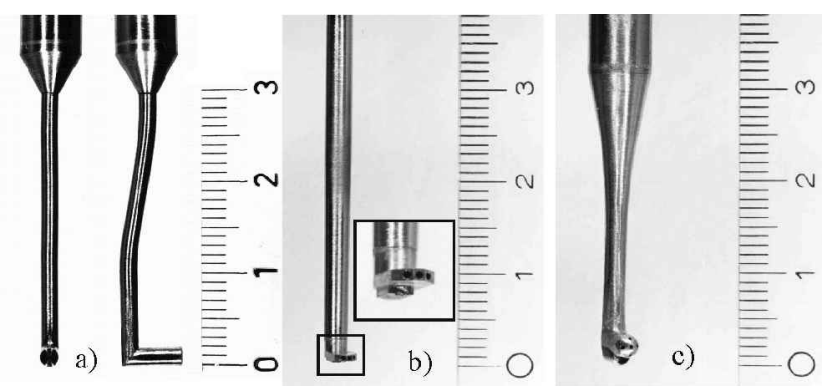

Fig. 3 Pneumatic probes: (a) total pressure probe with fastresponse semiconductor pressure transducer; (b) threehole pressure probe; (c) five-hole pressure probe 
hot-wire probes and a probe equipped with a single fastresponse semiconductor pressure transducer were applied in order to measure the unsteady three-dimensional velocity vector and total pressure respectively, with high resolution both in space and time. All probes used in the test rig were calibrated over a wide range of Mach numbers as well as yaw and pitch angles in order to cover the compressor operating conditions. Beside these probes, all stator rows were equipped with static pressure taps, flush-mounted hot films and semiconductor pressure transducers on the suction and pressure sides at different spanwise locations. The unsteady pressure field at the casing wall over the rotor blading was investigated with semiconductor pressure transducers (Kulite XCP-062-25D).

Figure 3 shows the total pressure probe equipped with a fast-response semiconductor pressure transducer (Entran EPIH-112) which was developed and manufactured at the institute. It turned out that the data acquired with this probe allowed a valuable visualization of the wakes generated by the rotor and stator blades as well as tip clearance vortices and contributed very much to the understanding of unsteady flow phenomena in the multistage compressor. Comparing, for instance, the time-resolved total pressure loss areas downstream of a rotor blade with the total pressure field in the exit plane of the stator blades downstream, it could clearly be detected how these loss areas are altered through the stator passages and where they are located. The time dependent signals of these probes were also used to quantify the upstream and downstream influence of the rotor blades. Examples of these results are presented in this paper.

Because of the superposition of periodical and random fluctuations, a direct physical analysis of the raw data is not possible. Therefore, methods such as ensemble averaging, Fourier transformation and time averaging were used for analysing the unsteady flow phenomena. The individual requirements of these calculation methods had to be considered during data acquisition. The Fourier transformation requires a long time signal to ensure a sufficient accuracy. The bandwidth is limited by the amplifiers, resulting in a maximum frequency of $109.5 \mathrm{kHz}$. However, a large number of short signals triggered at one rotor position are necessary for the ensemble averaging technique, which allows the separation of periodic and random fluctuations. A total of 256 time traces with 256 time steps were recorded. Using a sampling frequency of $250 \mathrm{kHz}$ and a high storage capacity of the acquisition system, at least seven rotor blade passing periods typically were recorded.

\section{EXPERIMENTAL RESULTS}

\subsection{Performance and stage characteristics}

Before describing the results obtained by unsteady flow measurement techniques, the off-design performance of this particular compressor will be characterized by some quantities of special interest. Figure $4 \mathrm{a}$ shows the total pressure ratio of all stages measured by pressure probes for the operating points on the 100 and 68 per cent speed line. For comparison purposes, the stage pressure ratio at design is also included. It is clear that the first stage exhibits the highest pressure ratio which then continuously decreases for the stages that follow. The measured pressure ratios of OP1 are almost identical to the design pressure ratio, being slightly higher for the first stage and slightly lower in stage 2 . It can clearly be seen that throttling at the two speed lines has a greater effect in the rear stage than in the first stage, as expected. However, this effect is much smaller for 100 per cent speed compared with 68 per cent speed. This can be explained by the larger operating range at the lower speed and the high aerodynamic loading of stator 3 (which was by design intent in order to study the effect of high loading). It can be shown by the detailed flow measurements that stator 3 has a significant corner stall in the hub region even at OP1 (close to the design point) (see reference [1] and Fig. 8).

Figure $4 \mathrm{~b}$ shows the average diffusion factor according to Lieblein et al. [7] for all bladerows according to the respective operating points and in comparison with design values. Looking at design speed and pressure ratio, it can be seen that the rotor blades of the first two stages exhibit a higher aerodynamic loading in comparison with the respective stator blades, but all at moderate levels. The diffusion factor is highest for stator 3, reaching values of 0.4 (measured) and 0.43 (design). Throttling at design speed (OP3) increases the diffusion significantly on all blades except for stator 3. This exhibits only a slight increase which may be due to the fact that already at the design pressure ratio a relatively high diffusion is present. It is assumed that surge of this particular compressor is triggered by stator 3 .
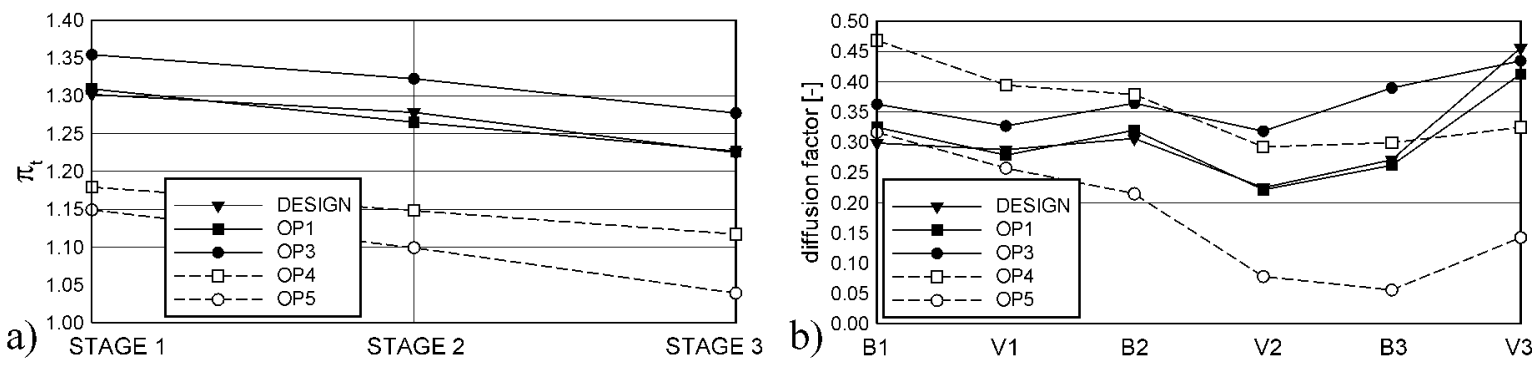

Fig. 4 (a) Total pressure ratio of all stages and (b) diffusion factor of all blades 
As expected, the rear stages exhibit a strong unloading at 68 per cent speed close to choke. Throttling the compressor at 68 per cent increases the diffusion significantly for all bladerows. It is rotor 1 in this case that experiences the highest diffusion level and reaches values of almost 0.5. Therefore, rotor 1 is likely to stall and trigger surge at this lower speed. Downstream of rotor 1 , the following bladerows are facing continuously lower diffusion levels. At 68 per cent speed the diffusion level of stator 3 close to surge is definitely lower than at design speed.

An additional assessment of the performance of the compressor can be made by the static pressure taps in the casing above the three rotor blades. Static pressure was measured by pressure taps at 24 axial positions for rotor 1 , 23 axial positions for rotor 2 and 22 axial positions for rotor 3 , and 25 positions in the circumferential direction in each case. The results are shown in Figs $5 \mathrm{a}$ and $\mathrm{b}$ along the dimensionless chord length of the three rotor blades. Looking at 100 per cent speed, the pressure rise over each rotor blade can be seen very clearly. At OP1 the flow is obviously accelerated upstream of the leading edge beginning roughly at -20 per cent relative chord, an effect which is much less pronounced at OP3. Throttling the compressor from OP1 to OP3 produces a significant pressure rise over the rotor blades. As expected, it is strongest for rotor 3. Of special interest is the change in performance at the lower speed. Comparing results at 68 per cent speed with 100 per cent speed, the pressure rise at OP4 over the rotor blades becomes much smaller. Unthrottling the compressor from OP4 to OP5 at 68 per cent speed still causes a continuous moderate pressure rise at OP5 over the first two rotor blades. Finally, rotor 3 initially causes the flow to accelerate up to about 20 per cent chord length, resulting in a pressure drop until again a pressure rise occurs. However, the exit pressure at rotor 3 exit is still lower than the static pressure at rotor 2 exit. As already shown in Fig. 4, stage 3 is strongly unloaded. Detailed flow traverses at the inlet planes revealed that this strong unloading caused large negative incidence flow angles, resulting in flow separations on the pressure side of stator 3 .

Summarizing the steady flow measurements, it can be concluded that:
1. Stator 3 already at design conditions (OP1) is at its load limit and defines the surge limit at design speed. The expected increase in loading by approaching the surge line does not show up.

2. At OP4 and OP5 on the 68 per cent speed line, the effect of speed reduction is dominant. Contrary to the design speed, the front stage becomes highly loaded while the rear stage is strongly unloaded. It is rotor 1 that defines the surge limit.

\subsection{Integral characterization of the unsteady flow field}

Since many measurements with different unsteady measurement devices at many locations inside the compressor and five different operating points were carried out, a huge database was generated. Looking at the plots and animations of time-resolved quantities at various locations in the compressor, a valuable insight into unsteady three-dimensional flow phenomena was obtained, i.e. interaction of wakes with boundary layers on bladerows located downstream, interaction of secondary vortices between adjacent bladerows, periodic potential upstream influence of blades, etc. This paper, however, does not deal with a detailed description of these flow phenomena, which will be given in future publications. During analysis of the huge database, the question arose as to how to summarize and describe the observed unsteady flow phenomena and effects adequately on a more global scale by a suitable quantity or evaluation procedure.

During the data analysis it turned out that, in particular, the data acquired with the total pressure probe equipped with the fast-response semiconductor pressure transducer were very valuable in order to visualize, quantify and better understand the unsteady flow phenomena in the three-stage axial compressor. The data measured by the total pressure probe provide not only ensemble-averaged and r.m.s. values but also the specific frequencies at each data point. Each frequency spectrum consists of 32.768 frequency lines with a distance of $7.63 \mathrm{~Hz}$. As an example, Fig. 6 presents a particular measuring point in the inlet plane of the second stator. The peaks induced by the rotor blades can clearly
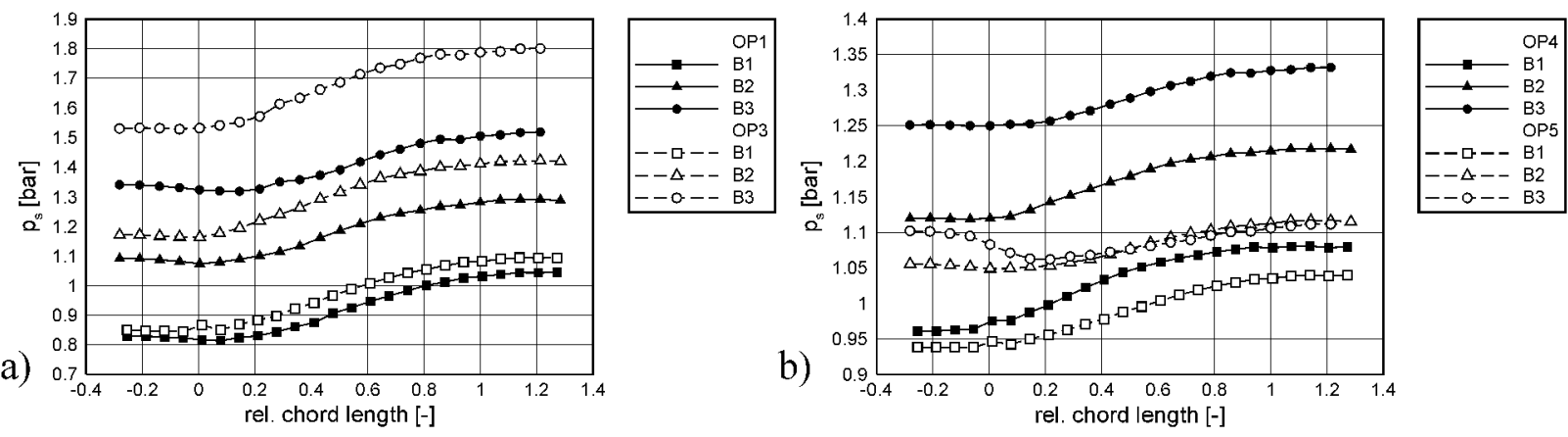

Fig. 5 Wall static pressure distribution at the casing above all rotor blades: (a) 100 per cent speed (OP1 and OP3); (b) 68 per cent speed (OP4 and OP5) 


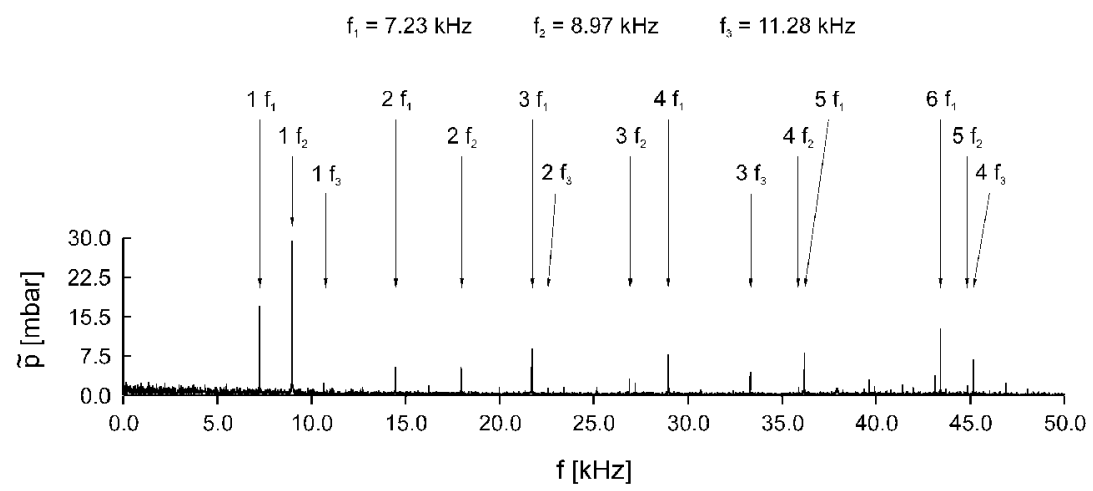

Fig. 6 Typical frequency spectrum in the inlet plane of stator 2

be seen and identified by the frequencies generated by the three rotor blades.

The sum of all amplitudes $\tilde{p}_{j}$ of such a spectrum is a measure of the total energy of the pressure fluctuations. By summing up the amplitudes $\tilde{p}_{\text {harm } i, k}$, which are obtained by the higher harmonics of the three blade passing frequencies $f_{1}, f_{2}$ and $f_{3}$ (marked in Fig. 6), the periodic parts of the pressure signal that are generated by each particular bladerow can be obtained. If both quantities are related to each other, a characteristic parameter $K_{\mathrm{p}}$ can be defined for each blade $i$, which describes the contribution of periodic fluctuations of a particular bladerow relative to the total unsteady pressure signal

$$
K_{\mathrm{p} i}=\frac{\sum_{k=1}^{10} \tilde{p}_{\text {harm } i, k}}{\sum_{j=1}^{N} \tilde{p}_{j}}, \quad i=1,2,3, \quad N=32768
$$

The calculation of $K_{\mathrm{p}}$ was performed for all measuring planes and operating points. The first ten harmonics were considered, i.e. $k_{\max }=10$. A representative value was obtained by arithmetic averaging of all measurement points in one exit plane. Plotting all these values along the machine axis clearly shows the influence of the pressure fluctuations of each bladerow in terms of strength in each measuring plane and their upstream and downstream influence.

Figure $7 \mathrm{a}$ shows the plot of characteristic parameter $K_{\mathrm{p}}$ for operating points OP1 and OP3, both on the 100 per cent speed line. The axial distance of measuring planes along the abscissa is to scale. The different symbols distinguish between the three blades, whereas the type of lines (solid/ dashed line) is related to different operating points as indicated in the legend. It needs to be mentioned that the frequency spectra also contain a band of white noise (besides the peaks described above) which can be attributed to the stochastic parts of the signals and are caused by turbulent flow phenomena. This white noise is why the characteristic values of $K_{\mathrm{p}}$ are never lower than 1 per cent even if the pressure signal is free of influence by the rotor blade. At both operating points on the 100 per cent speed line the distributions of $K_{\mathrm{p}}$ exhibit a similar trend, although some differences can be discerned.

Figure $7 \mathrm{a}$ reveals that the value of $K_{\mathrm{p}}$ is highest for bladerow 1 , followed by blade 2 and is finally lowest for bladerow 3 . In other words, there is a tendency towards a continuously decreasing level of periodic blade influence in this particular compressor. This can be explained by airfoil loading (cf. Fig. 3) and blade thickness decrease along the machine axis, obviously resulting in equivalent lower periodic pressure fluctuations. Independently, the upstream and downstream influence of an individual bladerow is similar for all bladerows. While the upstream influence almost ends in the inlet plane of the stator row located upstream, the downstream influence can clearly be detected several rows downstream. For example, the characteristic parameter $K_{\mathrm{p}}$ reveals that periodic fluctuations are still present in the exit plane of the compressor which have their origin in the first rotor row, although their presence is not directly visible in
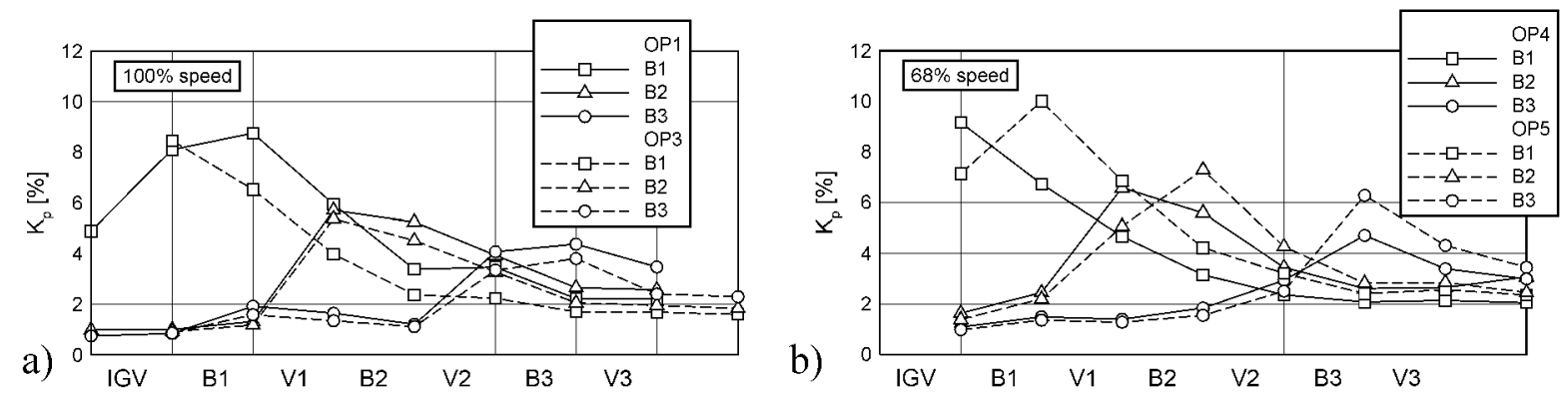

Fig. 7 Plots of characteristic parameter $K_{\mathrm{p}}$ 


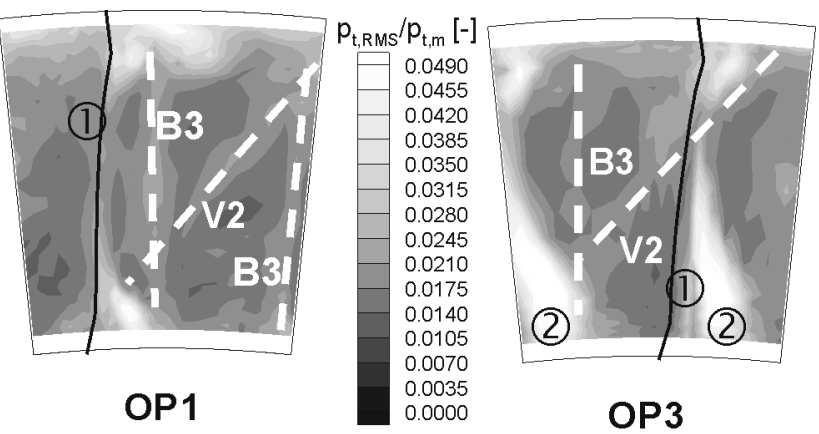

Fig. 8 Instantaneous total pressure fluctuation (r.m.s. values) in the exit plane of vane 3

the respective plots or animations, (see Fig. 8) (note also the large hub corner stall of vane 3 at OP3, indicated by (2)). Figure 8 shows the r.m.s. values of the instantaneous total pressure $p_{\text {t,r.m.s. }}$ related to the time- and area-averaged total pressure $p_{\mathrm{t}, \mathrm{m}}$ in this particular measurement plane.

A direct analysis of the animated temporal plots shows the exact location of individual wakes produced by blade 3 and vane 2 . The line indicated by (1) is the theoretical position of the trailing edge of vane 3 in the measurement plane, traced by using the radial distribution of the measured time-averaged flow angle. At the same location the wake of vane 3 can be identified. Additional wakes produced by airfoil rows further upstream cannot be identified by visual analysis. However, parameter $K_{\mathrm{p}}$ is obviously more sensitive since it depicts even pressure fluctuations produced by bladerows 1 and 2 in this measurement plane. This demonstrates that the proposed parameter $K_{\mathrm{p}}$ is very suitable for tracing wakes and secondary flows, and the results reveal their stability over several airfoil rows in this multistage axial compressor.

In the case of blade 1 , there is a distinct difference between OP1 and OP3. Contrary to OP1, the upstream influence at OP3 is larger than the effect produced by the wakes. Looking at blade 2, this phenomenon is no longer present. The value of $K_{\mathrm{p}}$ is almost identical in the exit plane of the IGV for both operating points, which is also confirmed by the distribution of instantaneous total pressure fluctuations $p_{\mathrm{t}, \mathrm{EA}}$ (ensemble average) (see Fig. 9). Note that in this case the ensemble-average value of the total pressure is chosen since it better captures the potential upstream influence of the blade than the r.m.s. values. Again, the total pressure fluctuations are related to the time- and areaaveraged total pressure in this particular plane. The line indicated by (3) is the theoretical position of the trailing edge of the IGV in the measurement plane, traced by using the radial distribution of the measured time-averaged flow angle. The IGV wake is almost at the same position.

Also, surface hot-film measurements at mid-span of the IGV clearly prove the upstream influence of the periodic pressure field generated by bladerow 1. Depending on the circumferential position of blade 1 relative to the IGV, either a bypass transition or a boundary layer separation in
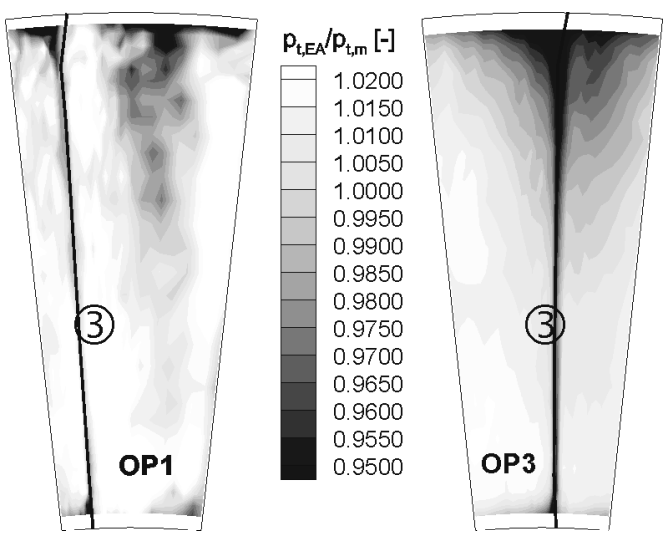

Fig. 9 Instantaneous total pressure fluctuations (ensemble average) in the exit plane of the IGV

combination with a laminar to turbulent transition occurred on the suction surface of the IGV (see reference [6]). This can be shown by the temporal development of the fluctuations of quasi wall shear stress $q_{\tau_{\mathrm{W}}}$ along the relative chord length $x / s$. The quantity quasi wall shear stress is used here as was first proposed by Hodson et al. [8], since a calibration of the individual hot-film sensors is not feasible. The results show almost an identical upstream influence of blade 1 for both operating points, which is in line with the parameter $K_{\mathrm{p}}$ in this plane (see Fig. 10). Another effect can be identified in the inlet plane of blade 2. At OP3 the upstream influence of blade 2 is even larger than the influence of the wakes produced by blade 1 . This is not the case for OP1. In the rear stage the unsteady flow phenomena become very complex, and an unambiguous separation of effects and tendencies with the integral method becomes very difficult, although the unsteady total pressure measurements allow a clear distinction between individual wakes produced by the different bladerows, as can be seen in Fig. 8.

At 68 per cent speed the differences between the operating points under consideration are even more pronounced, since a larger operating range between surge and choke has been covered. Similar to the 100 per cent speed line, the same trend between the two operating points becomes visible (see Fig. 7b). The downstream influence of the wakes is clearly lower for the operating point close to the surge line. Although the aerodynamic loading is higher for these operating points, the wakes are obviously less stable along the machine axis compared with the operating point closer to the choke line. Looking at the distribution of parameter $K_{\mathrm{p}}$ for OP5, it can clearly be seen that the upstream influence of all rotor blades is definitely weaker than the influence of the wakes of the upstream located bladerow. In the exit planes of all bladerows a strong influence of the wakes is present, which decreases continuously downstream. This phenomenon can also be shown by the time-resolved field traverses with the unsteady total pressure probe. Thus, it must be concluded that the unsteady flow phenomena are dominated by viscous flow effects for this operating point. 

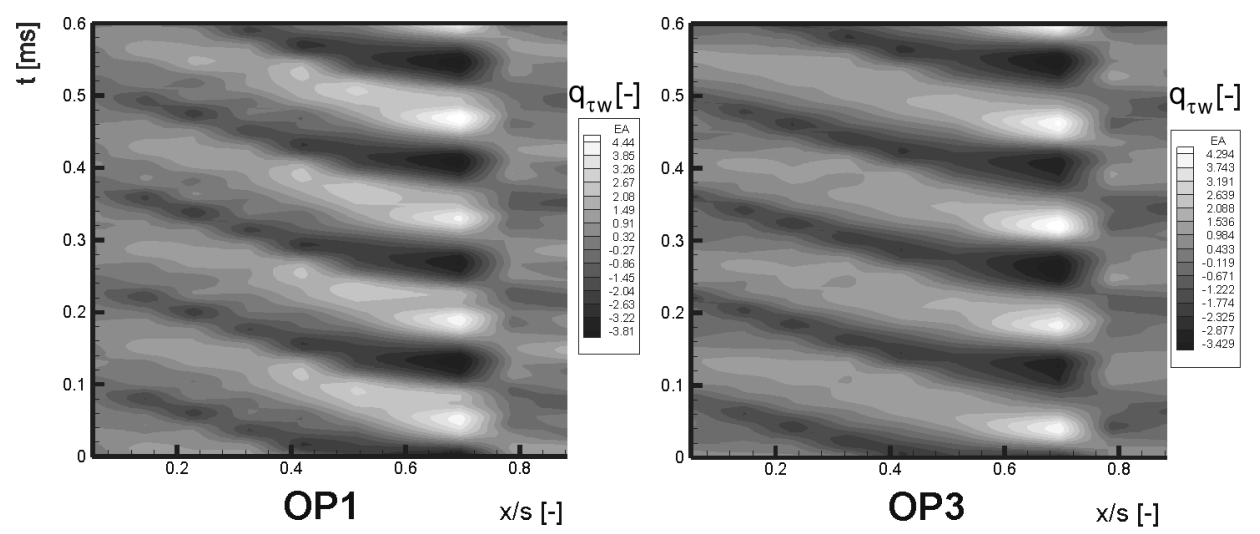

Fig. 10 Temporal development of the fluctuations of ensemble-averaged quasi wall shear stress along the relative chord length $x / s$ on the IGV on the suction side at mid-span

\section{CONCLUSIONS}

The flow inside a three-stage axial compressor with design features of real industrial compressors has been investigated in much detail by state-of-the-art steady and unsteady measurement techniques. In total, five operating points were investigated, resulting in a huge database that is a very valuable source for CFD code validation. Particular attention has been drawn to unsteady flow phenomena in this multistage component, such as stability and transport of wakes, periodic potential upstream influence, interaction between various bladerows and secondary flow phenomena. The measurement results contributed to a comprehensive understanding of these phenomena and many interesting flow details could be detected. However, it turned out that, besides the many details included in the measurement results, a more integral flow parameter would be beneficial in order to describe the relevant flow phenomena on a more global scale. Therefore, a parameter was defined that relates the sum of harmonic pressure fluctuations of each individual bladerow to the total pressure fluctuations in each measurement plane along the machine axis. Comparing the distributions of this parameter with the detailed flow measurements, it turned out that the proposed definition was able to represent many of the unsteady flow phenomena inside the compressor.

The integral representation of the unsteady flowfield inside the three-stage axial compressor with a CDA blading revealed the following characteristics:

1. The influence of the blades on the unsteady flowfield strongly depends on the operating point and the aerodynamic loading of the blades.

2. Unsteady total pressure and hot-film measurements reveal similar trends.

3. Basically, the potential upstream influence of the blades increases with aerodynamic loading.

4. With increased aerodynamic loading there is a decrease in the intensity and stability of wakes combined with a stronger mixing process.

\section{ACKNOWLEDGEMENTS}

This work was supported by the Forschungsvereinigung Verbrennungskraftmaschinen e.V. (FVV) and the Arbeitsgemeinschaft Industrieller Forschungsvereinigungen e.V. (AIF), which is gratefully acknowledged.

\section{REFERENCES}

1 Hoynacki, A., Gallus, H. E. and Niehuis, R. Unsteady flow phenomena in a three stage axial compressor with controlled diffusion airfoils. Proceedings of International Gas Turbine Congress, Kobe, Japan, 1999, Vol. 1, pp. 575-582.

2 Barankiewicz, W. S. and Hathaway, M. D. Effects of stator indexing on performance in a low speed multistage axial compressor. ASME 97-GT-496, 1997.

3 Hsu, S. T. and Wo, A. M. Reduction of unsteady blade loading by beneficial use of vortical and potential disturbances in an axial compressor with rotor clocking. ASME 97-GT-27, 1997.

4 Walker, G. J., Hughes, J. D., Köhler, I. and Solomon, W. J. The influence of wake-wake interactions on loss fluctuations of a downstream axial compressor. ASME 97-GT-469, 1997.

5 Walker, G. J., Hughes, J. D. and Solomon, W. J. Periodic transition on an axial compressor stator-incidence and clocking effects. ASME 97-GT-469, 1998.

6 Hoynacki, A., Gallus, H. E. and Niehuis, R. Unsteady boundary layer behavior in a three-stage axial compressor. In Proceedings of ISUAAAT, Lyon, France, 2000.

7 Lieblein, S., Schwenk, F. C. and Broderick, R. L. Diffusion factor for estimating losses and limiting blade loadings in axial flow compressor elements. NACA RM E53D01, 1953.

8 Hodson, H. P., Huntsman, I. and Steele, A. B. An investigation of boundary layer development in a multistage LP turbine. Trans. ASME, J. Turbomach., 1994, 116, 375-383. 